\title{
The failure of the American ABC HIV prevention model in Botswana
}

\author{
Yvonne Su*

\begin{abstract}
*This manuscript was prepared under the supervision of Professor Jacqueline Murray, Department of History, College of Arts, and Alastair Summerlee, President and Vice-Chancellor, University of Guelph, Guelph, Ontario, Canada
\end{abstract}

\begin{abstract}
This paper argues that the American ABC (Abstain, Be Faithful, and Condomise) HIV prevention model has failed in Botswana as a result of cultural irrelevance, the imposition of dominant American Christian ideals and a lack of local involvement and consultation. The paper will first examine the development of the American ABC Model and how it is distributed in Botswana. The second section will demonstrate the cultural irrelevance of the ABC model by examining the sexual practices of four ethnic groups within Botswana: the Bakalanga, Bangwato, Basarwa, and Baherero. The breakdown of the ABC model and its irrelevance to Botswana culture will demonstrate how the export of dominant American Christian ideals have strongly ignored and undermined sexual norms and practices. Lastly, the paper will demonstrate the importance of including local actors such as chiefs and indigenous NGOs in effectively deal with the HIV and AIDS epidemic in Botswana.
\end{abstract}

n 2008, there were an estimated 33.4 million [31.1 million - 35.8 million] people living with human immunodeficiency virus (HIV) in the world [1]. SubSaharan Africa was most heavily affected by HIV, accounting for $67 \%$ of all people living with HIV and for $72 \%$ of acquired immune deficiency syndrome (AIDS) deaths in 2008 [1]. In one Sub-Saharan country, Botswana, HIV prevalence for adults aged 15 to 49 is approximately $25 \%$ which places it second in global HIV prevalence after Swaziland [1]. Since 1987, international agencies have run a multitude of prevention and awareness campaigns to try to decrease HIV prevalence. However, more than 20 years later, HIV and AIDS is still described as the single greatest development challenge in Botswana. This paper examines some of the reasons for this failure which relate to the cultural irrelevance of the American ABC (Abstain, Be Faithful, and Condomise) model in Botswana.

\section{ORIGIN OF THE AMERICAN ABC MODEL}

It is important to establish how the $\mathrm{ABC}$ message was initially developed within the western context in order to understand its irrelevance to Bostwana. The first cases of AIDS were reported in the U.S.A in the early 1980s, primarily among gay men in New York and California. The initial response from the U.S. government was to develop AIDS prevention programs that focused on risk reduction [2]. As a result, condoms were provided to reduce the risk of sexually transmitted HIV infection. After further studies by the U.S. Centers for Disease Control in 1981, three main behavioural modifications were advised: reducing the number of sexual partners, eliminating the exchange of body fluids during sex, and 'knowing your partner' by avoiding places characterized by sexual anonymity [3]. These behavioural modifications became known as the "safe/r" sex model and was originally designed for homosexual men [4]. For heterosexual people, instead of a safe/r sex model, an "abstinence-until-marriage" model was recommended. This model was supported by the U.S. government and in 1981 an "abstinence-until-marriage" program was distributed across America to teach that abstinence from sex until marriage is the only effective method of HIV prevention [5]. The program was developed based on dominant American Christian values which hold that sex should only take place in the context of marriage [6]. The main objective of abstinence education is to equip young people to refuse or avoid sex. Even though the prevention model had not been named the "ABC campaign" at that time, the concepts and ideology behind the campaign were being developed.

In 1987, when U.S. organizations began to sponsor AIDS education in Botswana, the B for be faithful and C for condomise in the $\mathrm{ABC}$ campaign were taken from the safe/r sex model and the A for abstinence was added as a result of conservative American Christian beliefs in abstinence-untilmarriage [7]. This information led to the creation of the basic components of the American ABC model which was essentially an amalgamation of various best practices from homosexual communities and Christian interest groups in 
America. From this brief historical background on the development of the ABC model it can be seen that many of the concepts were developed within the western context of the United States. The ABC model was not developed for the international community, nor was it developed to be flexible to varying sexual practices found within other countries. Thus, the program cannot be expected to be applicable and well received in countries that do not share a similar western culture.

Despite these concerns, the U.S. government is supporting the ABC model in various developing countries through the United State's President's Emergency Plan for AIDS (PEPFAR). In January 2003, the United States pledged $\$ 15$ billion to global AIDS under PEPFAR. Under PEPFAR, the ABC model was adopted as the model for HIV prevention for generalized epidemics [8].

\section{$A B C$ and PEPFAR}

PEPFAR's exclusive support for the ABC model is having a direct impact on the types of HIV prevention programs that can be run. PEPFAR is very specific about the types of programs that it will fund and ones that it will not. Both of these funding specifications are as a result of the conservative Christian American ideologies that govern PEPFAR. In 2008, PEPFAR was reauthorized and the guideline states that "In countries with generalized HIV epidemics, at least half of all money directed towards preventing sexual HIV transmission should be for 'activities promoting abstinence, delay of sexual debut, monogamy, fidelity, and partner reduction” [9]. PEPFAR promotes the use of condoms for people in high risks groups only. PEPFAR does not fund condom-only programs and any programs that includes a condom component must be coupled with information about "abstinence as the only $100 \%$ effective method of eliminating risk of HIV infections, and the importance of HIV counseling and testing, partner reduction, and mutual faithfulness as methods of risk reduction" [9]. Thus, it can be seen that funding from PEPFAR is driven by Christian American ideologies of sex and through its selective funding schemes; HIV prevention programs are exporting these ideas across the globe. Furthermore, the strict funding guidelines are motivating local NGOs to manipulate their programs to accommodate PEPFAR's specifications. Scholars have noted their concerns that the growing dependence on foreign aid will affect the relationship between NGOs and the population they serve. Their main concern is that NGOs may stray from grassroots and culturally appropriate programs as western donors and their agendas become their new constituents [10]. This may have serious implications for the effectiveness of these organizations and their ability to help those infected and affected by HIV and AIDS. An example of groups not receiving help are groups who advocate and program for homosexuals and sex workers [11]. Although these two populations are greatly affected by HIV and AIDS, organizations that outreach to these groups will not be receiving help from PEPFAR.

Furthermore, scholars and the international community have criticized PEPFAR's ABC message for providing misguided information. Promoting abstinence-until-marriage alludes to the idea that marriage is a form of protection from infection. This is untrue and creates a false sense of security as many people are unaware of the HIV status of their partners and both partners need to be mutually faithful and uninfected to ensure HIV prevention [12]. Promoting condom use exclusively to high risk groups discourages the use of condoms for sexually active people who do not fall under the high risk groups. The promotion of condoms to sexually active populations is important as research has found that prevention strategies lose their potential effectiveness if people do not have access to condoms [13]. Many AIDS organizations have raised concerns about PEPFAR's strong emphasis on abstinence-until-marriage and its lack of focus on condom use among young people [14]. Despite these concerns, PEPFAR continues to provide funding for programs that emphasis abstinence-untilmarriage and ones that do not address condom use. In 2008 alone, PEPFAR donated \$24 million towards prevention activities in Botswana which specify funding towards preventing sexual transmission through ABC programs [15]. This type of favouritism in funding is evident in Botswana where out of the 25 organizations that received PEPFAR funding in 2008, only two promote correct and consistent condom use [16]. This type of disparity in funding is negatively affecting the types of programs that are available. As the main funding source in Botswana for HIV and AIDS programming, PEPFAR is making it difficult for programs to be successful without following the ABC model. Thus, support for abstinence-only education through PEPFAR is limiting young people's access to comprehensive sexual health education and effective risk reduction strategies in Botswana.

\section{Cultural IrReleVANCE OF THE AMERICAN ABC PreVention Model in BotsWANA}

To understand how culturally irrelevant the American ABC message was for Botswana, one must first understand the cultural dimensions of sexuality in Botswana. Ntseane and Preece's research on the sexual behaviour and experience of five ethnic groups in Botswana has revealed with unwavering consistency that:

1. For all ethnic groups, sex has a social function, including procreation, pleasure, family property, exchange, personal interaction, healing/cleansing, religion/spirituality interrelationships, and control/oppression.

2. Sex is culturally regulated, and accepted types of sexual behaviours are learnt through socialisation. 
3. Each ethnic group has access to national HIV/AIDS education processes but they felt the message has ignored the cultural sex and health education with which most people identify" [17].

These findings demonstrate the cultural dimensions of sexuality; the different functions of sex and how sex is regulated and learned within ethnic groups. Furthermore, it shows that ethnic groups do not agree with the national HIV and AIDS education processes as they feel their messages have ignored the cultural sex and health education of their group. Thus, any form of education or campaign aimed at changing sexual behaviour must first recognize those cultural dimensions and create programs that are based on of those fundamental cultural norms. Programs that disregard the cultural norms and sexual practices of a society will inevitably fail due to cultural irrelevance, as seen in the case of the American ABC HIV prevention model in Botswana.

The American ABC message of "abstain, be faithful and condomise" has failed in Botswana because it has overlooked the cultural dimensions of sexuality and the traditional sexual practices of different ethnic groups. This will be demonstrated through a breakdown of the ambiguity and cultural irrelevance of each component of the ABC, respectively. Examples of general sexual practices of Botswana and southern Africa and unique sexual behaviours of five ethnic groups from the anthropological research of Ntseane and Ntseane and Preece, will provide context for the arguments. Four out of the five ethnic groups are chosen to act as examples for this paper. The four ethnic groups highlighted in this section are Bakalanga, Bangwato, Basarwa, and Baherero. Using examples of the various cultural sexual practices of different ethnic groups, it will become clear why the American ABC HIV prevention model was culturally insensitive and, thus, ineffective in changing sexual behaviour and lowering HIV prevalence rates in Botswana.

\section{Ambiguity and Cultural Irrelevance of $A, B$, and C}

Dominant Christian American ideologies of abstinence and fidelity are not values that are shared by people of Botswana, and western inventions, such as condoms, have never before existed in the society. Thus, the exportation of these foreign ideas to Botswana has not only been ineffective in changing behaviour but has also perpetuated the erosion of traditional social practices and cultural norms. Through criticism of each component of the American ABC model, the ambiguity and cultural irrelevance of the model will become clear.

Abstinence. Under PEPFAR's definition of the ABC model, abstinence-before-marriage was heavily stressed. However, the inherent ambiguity of the term and PEPFAR's lack of a clear definition of abstinence makes abstinencebased prevention models subjective and inadequate [12]. Under PEPFAR's ABC Guidance \#1, “[a]bstinence programs encourage unmarried individuals to abstain from sexual activity as the best and only certain way to protect themselves from exposure to HIV and other sexually transmitted infections". Yet, what does abstinence mean, and what is the definition and scope of such "sexual activit[ies]" that one should abstain from? Abstinence is often defined as a voluntary restraint from indulging in sexual desires such as postponing first sex or avoiding further intercourse if already sexually experienced. However, this definition can be interpreted in different ways depending on one's views on sexual expression and the definition of sex. Touching, dry kissing, wet kissing, mutual masturbation, non-penetrative sex, dry vaginal intercourse, wet vaginal intercourse, oral sex, and anal sex, are just a few modes of sexual expression that may or may not be included in someone's perception of abstinence [12]. Thus, without a clear definition of sex or abstinence, HIV prevention programs that promote abstinence "as the best and only certain way to protect themselves from exposure to HIV" [18], can give people false risk perceptions. For example, someone who views sexual activity as exclusively penetrative sex may engage in oral sex and unwittingly be at risk of HIV infection. Thus, by not defining abstinence and sex in the PEPFAR ABC model, the individual must judge which behaviours are deemed sexual and non-sexual. This can result in an increase in HIV infections if individuals are making sexual choices based on a skewed risk perception that implies a subjective definition of abstinence.

In terms of cultural irrelevance, abstinence education ignores Botswana's cultural attitudes toward fertility. Botswana has one of the highest fertility rates in SubSaharan Africa; particularly for young unmarried women [19]. There are a multitude of contributory factors that support Botswana's cultural attitudes towards fertility: Bakalanga ethnic group's practice of Nkazana, humility associated with infertility, traditional beliefs of cleansing blood through childbirth, and beliefs that condone intergenerational sexual relations. These are also reasons why abstinence-based models of HIV prevention are ineffective in creating behavioural change among young people. By examining the factors that contribute to Botswana's high fertility, it is clear that the social importance of fertility supports cultural norms that regulate and control when young people are expected to have sex. Thus, the Christian American ideals of abstinence, delayed first sex and abstinence-until-marriage, are culturally irrelevant in Botswana as Batswana does not share these ideals.

The importance of fertility is highlighted in the Bakalanga ethnic group's practice of Nkazana, or the "younger wife" sexual practice. As an elderly woman stated in her interview with Ntseane, "the practice of Nkazana is important in our culture because marriage is for procreation and there is no divorce. So if this woman cannot conceive for whatever health reason Nkazana's children are officially hers. When she gets older or does not satisfy the husband sexually Nkazana is already there”. This quotation highlights 
the importance of fertility and procreation in Bakalanga culture. Thus, the sexual practice of Nkazana is in place to help ensure the successful conception of children for the family.

Other factors that contribute to the high fertility of Botswana is the belief that having a child proves one is a real man/woman [20]. A person's status is closely tied to his or her capacity to reproduce. As a result, there is a great deal of embarrassment associated with infertility. In traditional Tswana society, a married woman who failed to have a child would often be neglected and ill-treated by her husband [21]. To avoid such humiliation, many women choose to have a child prior to marriage to prove their fertility. As well, the high value that society attaches to children puts pressure on young people to have children. These cultural realities make it difficult for youth to adhere to ideas of abstinence-beforemarriage, or abstinence in general, as it goes against cultural norms.

Another factor that contributes to the high fertility rate is the Tswana belief that childbirth cleanses a women's womb. The number of children a woman has is a determinant of her cleanliness. Therefore, a woman who does not have many children is unclean, a status that is undesirable in Tswana society. This idea is based on the old Tswana belief that semen that is collected inside of the women's body from intercourse is eventually cleansed through childbirth [21]. This concept is supported by the belief that menstrual blood is dirty and that "only heavy bleeding during childbirth will purify the woman's body" [21]. Therefore, social pressures to purify a woman's body through childbirth may contribute to the high numbers of premarital sex and teenage pregnancy that are currently being observed in Botswana. Such embedded cultural ideas and beliefs cannot be easily undone by foreign ideas of abstinence.

Another Tswana belief surrounding the cleansing of blood is the belief that one way for older people to cleanse their blood and regain some of the vitality of youth is to have sex with a younger person, preferably a very young one [22]. The traditional rationale behind this belief is that "old men who marry young wives often seem younger than their actual age" [22]. This type of phenomena is observed in other cultures but the significance of the Tswana case is how the culturally constructed explanation of illness and the aging process can recommend intergenerational sexual relations as a health measure. In the context of HIV and AIDS, this cultural belief, along with men's power over women, puts young girls in a vulnerable position. To refuse sexual requests from men in high social or kinship positions, such as teachers or mother's brothers, is almost impossible for a young girl [22]. Thus, the gender inequality that exists in Botswana puts cultural restraints on a women's ability to abstain or delay first sex.

In the patriarchal society of Botswana, women do not have power in sexual decision-making. Thus, abstinence education is an inadequate approach to HIV prevention, because it is based on unrealistic assumptions that young women and girls in Botswana have the power to choose when and with whom they will engage in sexual activity [12]. Botswana's strong values of fertility, as demonstrated by the Bakalanga ethnic group's practice of Nkazana, traditional beliefs of cleansing blood through childbirth, and socially constructed ideas about intergenerational sexual relations as health measures, prove that simply telling women and girls to abstain from sex is an inadequate and culturally irrelevant solution to preventing HIV in Botswana.

Be Faithful. PEPFAR's definition of faithfulness is "fidelity in marriage and monogamous relationships" [8]. This simple message falsely assumes that marriage and monogamy inherently provide individuals who practice fidelity protection from HIV exposure [12]. This is not the case. Risk of HIV infection only decreases when both partners are HIV negative and mutually faithful. However, in Botswana polygamy was legal until recently but many cultural norms and traditions continue to support the practice of polygamy. Thus, marriage and monogamous relationships do not ensure sufficient security against HIV infection. Furthermore, although polygamy has been outlawed, it continues to exist in its modern form through concubinage. Concubinage occurs as a result of urbanization which causes many men to leave their village in search of work in the urban areas. This leads to the separation of a husband from his wife and in these circumstances a man will find temporary sexual partners in the city [23]. The increased number of sexual partners from diverse cultures and sexual backgrounds heightens the risk of HIV infection. Furthermore, due to economic hardships that result from poverty, many youth and single women engage in unprotected sex in exchange for money and other basic necessities [24]. As a result of such exchanges, the women and men are at higher risk of contracting HIV. Men who are infected in the city will subsequently bring the virus to their faithful wives back in the village. Consequently, although the wives practice low risk behaviours and remain faithful, they are still at risk of HIV infection because of their unfaithful husbands. PEPFAR states "once a person begins to have sex, the fewer lifetime sexual partners he or she has, the lower the risk of contracting or spreading HIV" [8]. PEPFAR's individualistic approach to behavioural change in terms of fidelity misleads people to believe their personal commitment to their partner by itself will help keep them safe from HIV infection. It is usually the same partner to whom they are faithful that ends up infecting them [1]. This is not true if their partner is unfaithful. Thus, the absence of a focus on mutual fidelity is misinforming women of risk perceptions and effective methods of prevention.

In terms of cultural irrelevance, the "be faithful" message is culturally insensitive to countries that permit legal polygamy or practiced polygamy in the recent past, such as Botswana. Although polygamy is no longer legal, many social norms and sexual practices still support 
polygamy. Through an analysis of the various polygamous practices of different ethnic groups, the cultural norms that support polygamy will be highlighted and the cultural irrelevance of the Christian American message of "be faithful" will become evident.

Different ethnic groups practiced and continue to practice unique sexual traditions that were necessitated by the mobility of their group. This is evident in the Bangwato's traditional practices of mantsala, playful sex with a blood or ethnic cousin and setogolo ntsha dithogo, young girls' playful sex with her mother's brothers. These practices were put in place to accommodate the seasonal migrations between the cattle post, land area and village. Thus, casual sex was seen as a sexual practice that was necessary to regulate sexual behaviours within this mobile ethnic group [24]. These practices are believed to reduce the people's exposure to sexually transmitted infections (STIs) and HIV, because sex is kept within the family. However, increased interactions with people from other cultures have caused sexual relations to occur outside of the family and ethnic group effectively disabling the protective function of the sexual practice by introducing STIs and HIV into the communities.

Other polygamous practices are seen among the Basarwa ethnic group with their practice of xakanaxaamaa, casual sex with any person. In Basarwa culture, any one in the clan is a potential sexual partner and sex can happen at any time [24]. Interestingly, in the context of HIV and AIDS, local Basarwa also blame the introduction of HIV on sexual relations with other ethnic groups, "[i]f some Basarwa girls were not sleeping with Bangwato we would not have AIDS in our community" [24]. Thus, it would appear that in the Bangwato and Basarwa culture it is more important to be faithful to your family and ethnic group as opposed to your partner. Betrayal and the breaking of cultural rules are associated with sleeping with people from other ethnic groups. Similar aversion for outsiders can be found in the resistance discourse that emerged in the late 1980s which blamed white foreigners for spreading the disease through sexual relations with Tswana girls.

Through the analysis of the unique sexual practices of mantsala, setogolo ntsha dithogo, and xakanaxaamaa, within the Bangwato and Basarwa ethnic groups, it can be seen that cultural practices and social norms still support and encourage sexual relations between multiple partners and faithfulness is with the family and ethnic group, not the individual partners. Christian American ideals of fidelity do not take into consideration Botswana's former polygamous society, current cultural practices that encourage sexual relations between multiple partners, and the modern realities of concubinage. Thus, the message of fidelity is culturally irrelevant and has been ineffective in reducing HIV prevalence in Botswana.
Condomise. PEPFAR promotes the "correct and consistent use of condoms for those who practice high-risk behaviors" [8]. Under their list of high-risk groups, youth are not listed. With almost half of Batswana under the age of 20, Botswana has a youthful population that is at risk of infection [25]. Nearly $45 \%$ of all new HIV infections in the world are among youth age 15-24 [26]. Therefore, by not including the promotion of condoms to young people within the PEPFAR definition of $\mathrm{ABC}$, the educational campaigns are not reaching a large portion of the population that is at risk in Botswana.

Aside from issues of inclusivity, a great deal of controversy surrounds the introduction of condoms into Botswana. As a foreign method of birth control and HIV prevention, the introduction of condoms has raised a great deal of skepticism and resistance. The new western based medical discourse of condom use and HIV prevention conflicts with traditional ideologies and embedded cultural systems of preventative herbs and healing. Thus, condom use was met with great resistance by local people and ethnic groups. Many people believed it was the condoms themselves that spread the HIV virus [17]. Others, however, believed it was an attempt by the western world to control the balance of power in Botswana,

\begin{abstract}
Men ask questions such as, where do these condoms come from? I am black or brown and just look at the colour [cream white] of the condom, it shows that it is from the West; it is another tactic of wiping out Africans from the face of earth. Unless you show me a factory of condoms in Botswana I can't believe it does not have AIDS [17].
\end{abstract}

This quotation suggests that suspicion surrounding condoms is due to xenophobia. As condoms and lubricants are methods that are not indigenous to Botswana, it is difficult to get local people to accept such a foreign invention into their sexual practices. Batswanas' lack of experience with similar western-based biomedical contraceptives leaves them skeptical of its effectiveness. A study conducted by Marandu and Chamme about different attitudes toward the effectiveness of condoms found that $38 \%$ of people do not use condoms because they believe that the AIDS virus can pass through the condom pores. 32\% of participants believe that condoms may malfunction; fail, break, slip out, during sexual acts. Moreover, 21\% believed that the use of condoms may cause cancer and $13 \%$ of participants believed condoms contain the HIV virus. Resistance to condom use is a result of conflicting discourses, specifically the suggested superiority of foreign discourse over traditional knowledge. This is a result of PEPFAR's disregard for effective traditional prevention remedies and cultural beliefs and values of fertility and sex. Through the examination of Tswana beliefs of the flow of health and wellness, cultural beliefs of marriage and sickness and the Baherero ethnic 
group's sexual practice of Otusira, the cultural insensitivity of condom use will be brought to light.

Blood and the state of blood is the key to physical wellbeing in Tswana culture. The transfer of blood between two people during sexual intercourse is health giving. Stopping this flow of blood through the use of a condom is seen as a possible cause of affliction with the blood becoming "hot" [27]. Thus, from the traditional perspective of blood flow between two people, condoms do not protect people but harm them.

Similar to the idea of connecting blood flows of health and well being during sexual intercourse, marriage also holds a special meaning. In the Bangwato culture, marriage joins two people in sickness and in health. This idea is taken quite literally in Botswana; meaning if one person gets sick so does the other. Thus, an elderly woman asked, "[h]ow can I listen to the people [western medicine] who do not understand my culture and ask my husband, cousin and any potential marriage partners to use a condom? I must be sick in my head" [28]. The unity between men and women in Tswana culture is so strong that blood and semen are called by the same word in Setswana, madi, which illustrates their symbolic connection [13]. Therefore, the use of a condom would block the culturally significant exchange of blood and semen between a man and a woman.

Last, condoms are irrelevant to specific cultural practices that involve unprotected sex such as Otusira, a sexual practice of the Baherero ethnic group. Otusira is the sexual practice of replacing the dead with a new born baby. The night of the vigil before the burial, tents are pitched at the bereaved family's residence and a small group of girls and men from the family of the deceased will engage in unprotected sex. This is done with hope that one of the girls will conceive the new child to replace the deceased. In the context of HIV and AIDS, it is stressed that sexual activities should be kept within the ethnic group because traditional medicines and spirits of the deceased ancestor's blessings are in place to prevent STIs. A young girl explains, "We are told by our grandparents and male sex partners that sex from Moherero to Moherero should be unprotected because you can not be infected with the HIV virus." This is echoed by another youth, "[i]n the urban areas we use condoms with boyfriends from other ethnic groups but with a Moherero boyfriend or cousin in Namibia I enjoy real sex because they will not accept a condom" [24]. This quotation highlights the false impressions of risk perception which are evident in each component of the ABC model. Without proper program that can effectively educate people on risk perception, unprotected sex with someone in the same ethnic group will always be considered to be safe. Through the examination of Tswana beliefs of the flow of health and wellness, cultural beliefs of marriage and sickness and the Baherero ethnic group's sexual practice of Otusira, it is clear that the foreign concept of condoms is one that goes against many of the traditional beliefs about health and wellness. As a result condoms have been ineffective in decreasing HIV prevalence in Botswana as many people are resistant to introducing a foreign invention into their sexual practices.

\section{FUTURE RECOMMENDATIONS FOR IMPROVEMENT OF HIV AND AIDS PREVENTION MODELS IN BOTSWANA}

The American ABC HIV prevention model has proven to be ineffective in changing sexual behaviour in Botswana as a result of its ambiguity, disregard for cultural values, norms and sexual practices and overall cultural irrelevance. Since PEPFAR implemented the ABC model in 2003, there has been no significant decline in HIV prevalence rates among adults. In 2003, UNAIDS had adult HIV prevalence for Botswana at 25.9\% [29]. Five years after the ABC model has been widely implemented, the adult HIV prevalence rate remains at approximately $25 \%$ in $2008 .{ }^{1}$ These statistics demonstrate that the $\mathrm{ABC}$ model did not dramatically reduce HIV prevalence rates in Bostwana as it had initially planned. This failure is largely attributed to the exclusion of local leaders, ethnic groups and communities in the creation of national HIV prevention campaigns which led to the development of untrustworthy and ineffective campaigns. Local people believe that Batswana were not given an opportunity to participate in the fight against the HIV and AIDS epidemic. In particular, traditional doctors perceived the initial lack of consultation as an insult to their good work. Traditional doctors have a very good understanding of their communities and hold a very influential position as a result of their work. They understand people's response to epidemics and are trusted within the community [24]. Thus, to ignore the knowledge and influence that traditional doctors and other local leaders hold can be interpreted as westerners not viewing their inputs as valuable. This lack of local involvement and consultation resulted in feelings of alienation towards public campaigns by the general public. Consequently, recommended behavioural changes promoted by the campaign were not trusted and actual behaviour change was minimal. Thus, in order for any HIV prevention campaign to be successful in the future, it must actively involve the opinions of local people. Traditional sexual practices, social pressures and cultural norms need to be considered. More importantly, local leaders need to be actively engaged in implementing prevention campaigns within the community. Ideas have been brought up to have traditional healers sell condoms from their home where they practice. The healers would be well educated about the origin, rationale, and correct use of the condom [28]. It is initiatives like this that will be powerful in reversing the trends of HIV in Botswana. Traditional discourse needs to be changed from within the society. Externally imposed discourses of medicine and individualistic intervention strategies have tried to change sexual behaviours in 
Botswana for the last two decades, yet Botswana continues to have one of the highest HIV prevalence rates in the world. Botswana's prevention programs must move away from externally imposed one-size-fits all approaches and head in the direction of grassroots, participatory community initiatives.

\section{REFERENCES}

1. UNAIDS \& WHO. (2009). AIDS epidemic update 2009. Retrieved on November 30, 2009 from http://data.unaids.org/pub/Report/2009/2009_epidemi c_update_en.pdf.

2. Green, E., \& Herling, A. (2006). Paradigm shift and controversy in AIDS prevention. Journal of Medicine and The Person. 4(1), 23-33.

3. King, E. (1993). Safety in numbers: Safer sex and gay men. London: Cassell.

4. Heald, S. (2002). It's never easy as ABC: Understandings of AIDS in Botswana. African Journal of AIDS Research, 1(1), 6.

5. Cohen, J., \& Tate, T. (2005). The Less They Know, the Better: Abstinence-Only HIV/AIDS Programs in Uganda. Reproductive Health Matters. 14(28), 174178.

6. AVERT. (2009). The ABC of HIV Prevention. Retrieved November 12th, 2009 from http://www.avert.org/abc-hiv.htm.

7. Casbarro, L., \& Jäger, J. (2007). The mistranslation of the ABCs: An American AIDS education campaign in Botswana. In S. M. Nielsen \& M. S. Plakhotnik (Eds.), Proceedings of the Sixth Annual College of Education Research Conference: Urban and International Education Section (pp. 7-9). Miami: Florida International University.

8. Office of The United States Global AIDS Coordinator. (2004). The President's Emergency Plan for AIDS Relief. Retrieved on November 11th, 2009 from

http://books.google.com/books?id=NOwfmJ8P3HUC \&printsec=frontcover\&source=gbs_v2_summary_r\&c $\mathrm{ad}=0 \# \mathrm{v}=$ onepage $\& \mathrm{q}=\& \mathrm{f}=$ false.

9. Office of The United States Global AIDS Coordinator. (2004). The President's Emergency Plan for AIDS Relief. Retrieved on October 21, 2009 from http://www.pepfar.gov/guidance/75852.htm.

10. Strain, R. (2008). Battle from the Bottom: The Role of Indigenous AIDS NGOs in Botswana. Retrieved on October 4, 2010 from http://repository.upenn.edu/ cgi/viewcontent.cgi?article=1096\&context=curej.

11. Igoe, J. \& Kelsall, T. (2005). Between a Rock and a Hard Place: African NGOs, Donors and the State. Durham, NC. Carolina Academic Press.

12. Tindall, T. (n.d.). International HIV/AIDS Prevention Programming: Not as Simple as ABC. Retrieved
October 21, 2009, from http://www.colorado.edu/ ArtsSciences/PWR/occasions/articles/Tindall_Internat ional\%20HIV\%20AIDS\%20Prevention\%20Program ming.pdf.

13. UNAIDS. (2004). 2004 Report on the global AIDS epidemic. Retrieved on November, 13th, 2009 from http://www.unaids.org/bangkok2004/GAR2004_pdf/ UNAIDSGlobalReport2004_en.pdf.

14. Office of The United States Global AIDS Coordinator. (2004). The President's Emergency Plan for AIDS Relief. Retrieved on October 21, 2009 from http://www.pepfar.gov/guidance/75852.htm

15. 15. U.S. State Department (2008). Botswana Fiscal Year 2008 Country PEPFAR Operational Plan (COP). Retrieved October 22, 2009, from http://www.pepfar.gov/about/opplan08/102036.htm.

16. SIECUS. (2008) SIECUS Releases 2008 PEPFAR Country Profile Updates: Show Rise of Abstinenceonly Providers Around the World. Retrieved on November $\quad 12, \quad 2009$ from http://www.lafamiliahabla.org/index.cfm?fuseaction= Feature.showFeature\&featureID=1496.

17. Ntseane, P., \& Preece, J. (2005). Why HIV/AIDS prevention strategies fail in Botswana: Considering discourses of sexuality. Development Southern Africa, 22(3), 347.

18. President's Emergency Plan for AIDS Relief (PEPFAR) Office of the U.S. Global AIDS Coordinator, (2006). ABC Guidance \#1 For United States Government In-Country Staff and Implementing Partners Applying the ABC Approach To Preventing Sexually Transmitted HIV Infections Within The President's Emergency Plan for AIDS Relief. Retrieved on November 11th, 2009 from http://www.state.gov/documents/organization/57241.p df

19. Gabe-Brandon, A. \& Meeker, D.(1993). Sex, contraception and childbearing before marriage in sub-Saharan Africa. Int. Family Planning Perspectives, 19(14). 48.

20. Marandu, E. E., \& Chamme, M. A. (2004). Attitudes towards condom use for prevention of HIV infection in Botswana. Social Behavior and Personality, 32, 491-510.

21. Macdonald, D. (1996). Notes on the socio-economic and cultural factors influencing the transmission of HIV in Botswana. Soc. Sci. Med. 42(9), 1325-1333.

22. Ingstad, et al. (1997). AIDS and the elderly Tswana: The concept of pollution and consequences of AIDS prevention. Journal of Cross-Cultural Gerontology. 12, 357-372.

23. Letamo, G. (1993). Modernization and premarital dyadic formations in Botswana. International Union for Scientific Study of Population. 1, 369-379. 
24. Ntseane, P., (2004). Cultural dimensions of sexuality: Empowerment challenge for HIV/AIDS prevention in Botswana. Department of Adult Education.

25. Hardy, P. \& Firestone, M. (2007). Botswana \& Namibia. Retrieved November 30, 2009 from http://books.google.com/books?id=HSAs1_B93YC\&source=gbs_navlinks_s.

26. Imanguli, N. (2008). Youth and the Global HIV/AIDS Pandemic. Retrieved on November 30, 2009 from http://www.advocatesforyouth.org/index.php?option= com_content\&task=view\&id=427\&Itemid=336.
27. Allen, T., \& Heald, S. (2004). HIV/AIDS policy in Africa: What has worked in Uganda and what has failed in Botswana? Journal of International Development, 16(8), 1141.

28. Ingstad, B. (1990). The Cultural Construction of AIDS and Its Consequences for Prevention in Botswana. Medical Anthropology Quarterly. 4(1), 2840.

29. UNAIDS. (2008). Adult (15-49) HIV prevalence percent by country, 1990-2007. Retrieved on October 24, 2010 from data.unaids.org/pub /.../20080813_gr08_prev1549_1990_2007_en.xls. 